\title{
Past4Future stakeholder survey
}

Henning Thing

Centre for Ice and Climate, Niels Bohr Institute, University of Copenhagen; thing@gfy.ku.dk

$T_{\mathrm{p}}^{\mathrm{n}}$ he European Union-funded Past4Future project aims at improving our knowledge of the climate system and the occurrence of abrupt climate changes during the last two interglacials, thereby paving the road for reducing the uncertainties in predicting future climate. The outcome of the project will eventually be globally disseminated and so far we have focused on the best way to communicate our results with citizens and policy-makers of the European Union.

For this purpose, we have (1) identified Past4Future stakeholders, (2) established a dialogue with them, using an online questionnaire, and (3) produced an assessment of their formulated needs and opinions. The online form presented 14 questions with a total of 78 multiple-choice options for answers as well as additional fields for entering detailed information. It took 10 to 12 minutes to complete the questionnaire.

\section{Past4Future Stakeholders}

We defined a Past4Future stakeholder as follows: an organization, a government agency, a commercial company or a community that has a direct or indirect stake in future climate change because it impacts its activities positively or negatively at a local, regional or global scale.

The aim was to receive feedback from at least 20 stakeholders. We identified and approached a total of 141 potential participants in very diverse positions, representing 22 European Union countries, Norway and the USA. The stakeholders were all contacted individually via targeted emails and friendly reminders. Unfortunately, we received feedback from only a few stakeholders: 18 people responded, but only 13 actually completed the questionnaire. Therefore, the opinions and comments expressed by the stakeholders in the review are based on these 13 feedbacks. A response rate of $9 \%$ illustrates how difficult it is to get the attention of the stakeholders although they have been individually approached and tended to. Our method obviously has not been successful; a personal face-to-face briefing with each stakeholder immediately before a paper-based questionnaire was scheduled would likely have produced a much higher response rate.

From the 13 stakeholders, seven come from the public sector (including politician, consultant, agency advisor), three are active in the private sector (e.g. consultant, media) and three are in the field of academia. Around half of the stakeholders operate in the strategic sphere, $30 \%$ conduct research and about $15 \%$ are in education fields.

\section{Interests and opinions of the Past4Future stakeholders}

However small the sample size is, the answers to the questionnaire form the foundation for assessing how to best present and disseminate the results and conclusions of the Past4Future project. This assessment is a first step to help the project partners to appraise stakeholders' interests and needs, the communication pitfalls and the recommended ways in which project activities and results must be communicated widely to the science community, among policymakers, other stakeholders, and to citizens of Europe and beyond.

Here are the main outcomes gathered from the 13 stakeholders:

Firstly, we consider their views on climate change projections: (1) These projections are most often used in a scientific context but stakeholders active in the public sector also use the projections for policy development (Fig. 1). (2) It is important for the stakeholders to know the exact information source, the assumptions made and the associated uncertainties. Stakeholders require projections on climate change risks to be founded in peer-reviewed sources or other sources of high credibility.

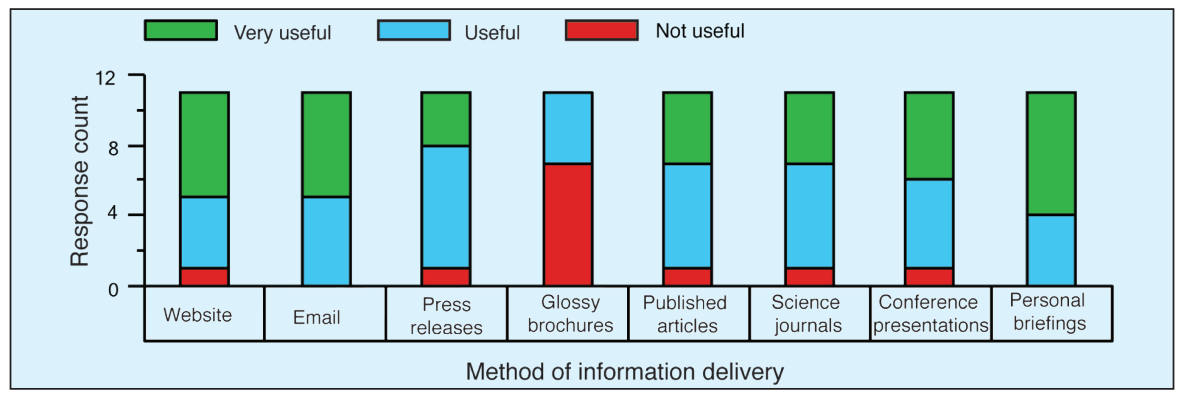

Figure 2: An excerpt from the stakeholder survey: feedback to the question "How useful to you are the following methods of information delivery?" 11 of the 13 stakeholders responded to whether they found the different methods of delivery very useful, useful or not useful. The remaining two stakeholders provided written feedback.

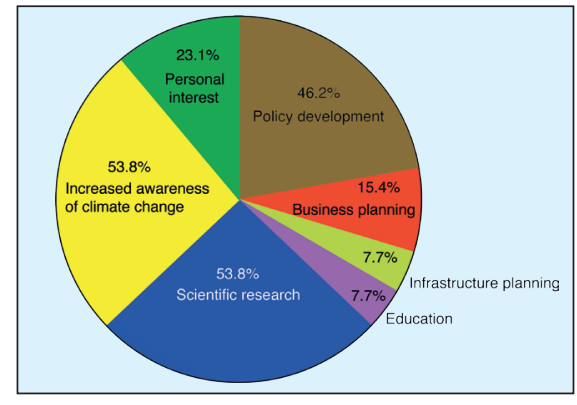

Figure 1:Anexcerpt from thestakeholdersurvey: Feedback to the question "In which contexts do you use projections aboutfuture climatechange?" Stakeholderswere allowed to select multiple answers since they can use future climate change projections in more than one context.

Secondly, their main scientific interests are in: (1) the anthropogenic increase of atmospheric greenhouse gas concentrations and (2) air and ocean temperature changes as well as sea level changes. The stakeholders are less interested in changes caused by solar and volcanic activity.

Thirdly, we consider their views on how to deliver the Past4Future project results (Fig. 2): (1) A personal briefing is preferred as the most useful method, supplemented by targeted information via email and website. (2) Press releases as well as written articles and conference presentations are considered useful means of delivering project results and conclusions. (3) Glossy brochures are deemed a waste of resources. In addition, most stakeholders estimate that information should be updated regularly.

Finally, in terms of the content, results should be delivered with an associated uncertainty. The stakeholder preference for this is an uncertainty that is expressed in "IPCC style" as they understand this concept. Again, they insist on the need to know the sources of uncertainty in the climate change projections.

\section{Outlook}

The delivery of Past4Future results into policy forums cannot be assumed and must be approached in a proactive manner. We will use forms, means and modes that will target the European perspective and impact our stakeholders. This will be achieved through various communicative products (including personal briefings, conference presentations, science journals, press releases, and public addresses) during the next two years, thereby enhancing Europe's ability to act timely and prudently while facing the challenges of the future climate. 